\title{
Some ethical concerns related to the coronavirus disease 2019 (COVID-19)
}

\author{
Ali Montazeri*1(10 \\ Received: 11 May 2020 \\ Published: 27 May 2020
}

\begin{abstract}
Although there are many important concerns related to coronavirus disease-19 (COVID-19), ethical issues should remain the top priority since the humanistic dimension of the recent pandemic is of prime importance. This short commentary highlights some ethical concerns related to (COVID-19). Political misuse, caring for older adults, and spread of harmful information are the 3 main issues that are addressed. It is hoped that those who can influence communities at large consider these issues for better public's health.
\end{abstract}

Keywords: Coronavirus, COVID-19, Ethics

Conflicts of Interest: None declared

Funding: None

*This work has been published under CC BY-NC-SA 1.0 license.

Copyright $\odot$ Iran University of Medical Sciences

Cite this article as: Montazeri A. Some ethical concerns related to the coronavirus disease 2019 (COVID-19). Med J Islam Repub Iran. 2020 (27 May);34:53. https://doi.org/10.47176/mjiri.34.53

\section{Introduction}

As the pandemic coronavirus disease 2019 (COVID-19) spreads worldwide, apart from many positive actions such as volunteer works and donations, we are witnessing a number of unpleasant and unethical actions that should be avoided. Here some ethical concerns are highlighted and it is hoped to be considered by all those who are involved.

\section{Political misuse}

In January 30, 2020 the World Health Organization (WHO) declared COVID-19 a global health emergency (1). The disease spread out globally and affected a large number of people. However, this situation should not be a ground for political battle among political parties within a country or among governments around the globe. To avoid any biases examples of such political challenges are not given here.

The COVID-19 is a serious disease, which is killing people at a large scale $(2,3)$, and thus it is not ethical to misuse such a condition to blame different nations or gov-

Corresponding author: Professor Ali Montazeri, montazeri@acecr.ac.ir

1. Population Health Research Group, Health Metrics Research Center, Iranian Institute for Health Sciences Research, ACECR, Tehran, Iran ernments. Health care workers and politicians should work together to deal with this horrible virus (4). They all should take responsibility for public health and help to overcome this global health problem. Political misuse of coronavirus is unethical and should be avoided, because if not addressed it may cause inequality in providing care and taking preventive measures.

\section{Caring for older adults}

One common recommendation to break the transmission chain is social distancing. Some may think social distancing means social isolation, while this is not the case, especially when we consider older adults who are living alone. Older adults should not be ignored or left to die of this disease. On the contrary, we should provide our seniors with best care to protect them from covid-19. They are our parents who brought up the generation and it is not fair and just to leave them alone.

$\uparrow$ What is "already known" in this topic:

Little has been discussed about ethical issues related to the COVID-19. It seems need more attention.

\section{$\rightarrow$ What this article adds:}

This short communication highlights three ethical concerns related to the coronavirus disease 2019. It discusses about political misuse, elderly care and spread of misinformation. 


\section{Spread of harmful information}

News about the COVID-19 either on the number of diagnosed cases or deaths due to the disease is usually the first topic in mass media and social media worldwide. The exposure of older adults and children to this amount of bad or even fear-inducing news should be avoided. These 2 vulnerable group should be treated with care and responsibility with regards to COVID-19 news. Circulating bad news especially in social media without any ethical commitments may severely harm old people and children. The source and the content of any news in mass media or social media needs careful and outmost considerations and should be scrutinized on the basis of ethical codes. The public health crisis emerging due to the coronavirus (COVID-19) has been worsened due to the effects of misinformation (5). Fake news or reflecting phantom science is similar to spreading coronavirus and may impact people emotionally (6) and harm vulnerable populations. A recent publication on misinformation and the US Ebola communication crisis reported that $10 \%$ of Ebola-related tweets contained false or partially false information, $25 \%$ were political in nature, $28 \%$ contained content that provoked reader response or promoted conflict (7). Thus, the impact of misinformation is not limited to children and elder population. There are high rank politicians and decisionmakers who are easily manipulated by fake news and misinformation around the world. Decisions of such powerful individuals can impose great harm to the general population.

\section{Conclusion}

This commentary highlighted only a few ethical concerns and many other ethical issues should be considered with regards to this pandemic. This hard time will not continue forever and hopefully will last soon. However, all communities will remember those who behave responsibly during this difficult time. We all should bear in mind that ethical considerations must be at the front line of our battle against the COVID-19.

\section{Conflict of Interests}

The authors declare that they have no competing interests. staff to common people. Brain Behav Immun. 2020;pii:S08891591(20):30411-6.

7. Sell TK, Hosangadi D, Trotochaud M. Misinformation and the US Ebola communication crisis: analyzing the veracity and content of social media messages related to a fear-inducing infectious disease outbreak. BMC Public Health. 2020;20(1):550.

\section{References}

1. World Health Organization. Coronavirus disease (COVID-2019) situation report-11. 31 January 2020. https://www.who.int/ emergencies/diseases/novel-coronavirus-2019/situation-reports. Accessed 4 April 2020.

2. World Health Organization. Coronavirus disease (COVID-2019) situation report-75. 4 April 2020. https://www.who.int/ emergencies/diseases/novel-coronavirus-2019/situation-reports. Accessed 4 April 2020.

3. World Health Organization. Coronavirus disease (COVID-2019) situation report-110. 9 May 2020. https://www. who.int/emergencies/diseases/novel-coronavirus-2019/situationreports

Accessed 9 May 2020

4. Murdoch D, Addidle M, Andersson HS, Arnold B, Balm M, Benschop J, et al. Politicians: please work together to minimise the spread of COVID-19. N Z Med J. 2020;133:7-8.

5. Mian A, Khan S. Coronavirus: the spread of misinformation. BMC Med. 2020;18:89.

6. Montemurro N. The emotional impact of COVID-19: from medical 